\title{
Theoretical Study of the Reaction of some Amino Alkyl Bromides with Hydrosulfite Ion in Acidic and Basic Media
}

\author{
Kasim Y. Rahawi \\ Abdul Majeed M. Dabbagh \\ Department of Chemistry \\ College of Science \\ University of Mosul \\ dr.kasim53@gmail.com \\ majdab48@yahoo.com
}

(Received 13/4/2011; Accepted 6/6/2011)

\begin{abstract}
Thermodynamic parameters of amino alkyl bromide with hydrogen sulfite ion have been investigated using computational methods in both acidic and basic medium. A semi-empirical method AM1 are performed to investigate the mechanism and factors affecting on the reaction route in both medium. The results led to the estimation of heat of formation and steric energy for reacting amines, transition states, intermediates and products. Our investigations have shown that the reaction process is affected by electronic factors and steric crowding. It is clarified that these factors play important role in the stability of the intermediates and is consistent with the previously proposed mechanism.
\end{abstract}

Keyword: Theoretical study of the reaction, Semi-empirical method AM1, Amino alkyl bromide.

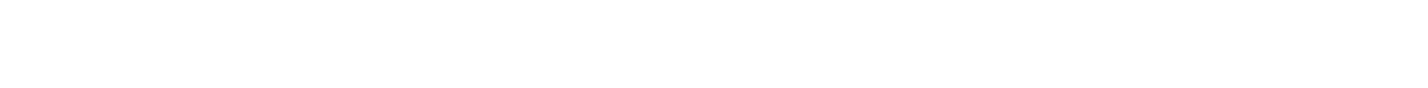 الهيروجيف بالوسطين الحامضي والفاعجي \\ الملغص}

قم في هذا البمث التحقق من بعض قيم العولمل الثرموداينمكية للفاعل بين عدد من مركبلت

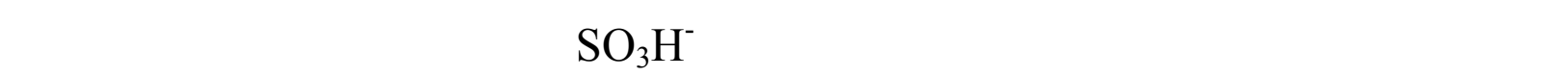
والقاعدي. وقد لستخدت طريقة AM1 شبه التجريبية للتحقق من ميكانيكية الفاعل والعوالمل المؤثرة

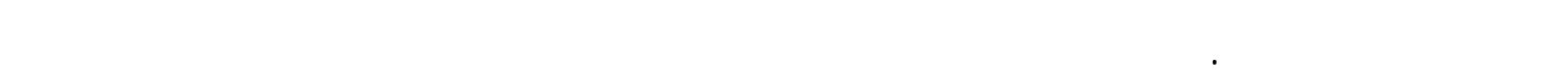

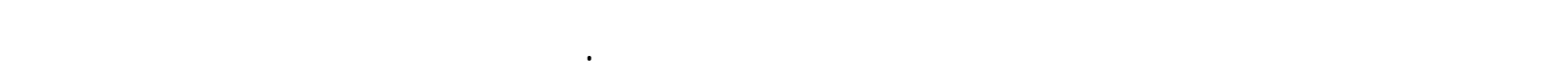

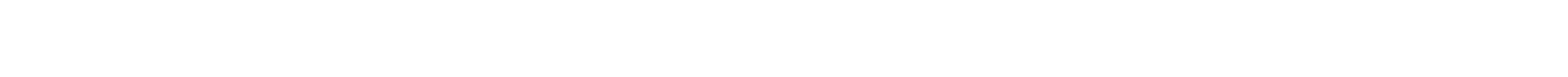
المركبت الوسطية، إذجاءت النتائج منسجمة مع الميكانيكية المقترحة مسبقاً. الكاملت الدالة : الدرلسة الظرية للفاعل،طريقة AM1شبه التجريبية، بروميد الألكل الأميني. 


\section{INTRODUCTION}

The reasonably acceptable chemical and physical properties along with their thermodynamic parameters rendered the amino alkyl bromides (AAB) to become suitable for a variety of industrial and medical applications (Guidotti, 1971). On the other hand, the amino alkyl sulfonic acids, (AASA), are considered to be very important for human life. Some are used for treating hypertension and hyperlipemia (Shigeru, 1972), others are useful as anticholesteremics (Tesuji, 1975). Many publications have been previously appeared dealing, in particular, with synthetic studies of these compounds (Sen, 1962), and to a certain extent with mechanism (Elvidge, 1981), others were concerned with the kinetic studies ( Ahmed, 1986; Dabbagh, 1996 and Saieed, 2005). Recently the effect of different substituents and ring size of reacting molecules on the rate constant for a set of bromoalkylamines have been studied theoretically using ab initio method (Najem, 2010). But to the best of our knowledge, no detailed work has been published on the computational studies of the heat of formation of such compounds.

Here we report a first complete computational work on the reaction of some amino alkyl bromides, $\mathrm{AAB}$, with hydrosulfite ion, $\mathrm{SO}_{3} \mathrm{H}^{-}$, in aqueous media which may be used to elucidate the mechanism of this process. Our conclusion for the formation of alkyl amino sulfonic salts in basic medium and bromo ammonium alkyl sulphonic acid are based on correlations of the electronic effects, of alkyl groups next to amino group, on the stability of the expected intermediate.

Computational methods have been introduced to allow analysis of reaction mechanisms and prediction of the reactivity in synthetic chemistry. To clarify the reaction mechanism and factors affecting this reaction, a semi-empirical calculation, AM1, is performed to obtain the optimized geometry, heat of formation, and some other physical properties of reactants, transition states, and products of the reaction of amino alkyl bromide with hydrosulfite ion to produce the above mentioned products.

\section{METHODS}

The AM1 method had proved to be highly reliable for calculating the physical properties of molecules. The MOPAC program package, version 11 was used. In our semi-empirical AM1 calculations, each of these structures was used as the starting point for the energy minimization. The energy minimizations were performed until the gradient was below 0.1 (Minimum RMS Gradient 0.1). AM1 method was used to calculate the heat of formation (HF), while the molecular mechanical method (MM2) was used to calculate the steric energy (SE). Both methods are applied for all substituted reacting amines, transition states, intermediates and products. SPSS programme version 17.0 was used for statistical calculations.

\section{RESULTS AND DISCUSSION}

In this paper, we represent a computational study of two series (A and B) of reactants, $(\mathrm{AAB})$, which react with hydrogen sulfite ion using a semi-empirical AM1 method. We confined ourselves to the investigation of the potential energy channels for both series in acidic and basic medium as shown below: 
Series A : proceeds according to the following route:

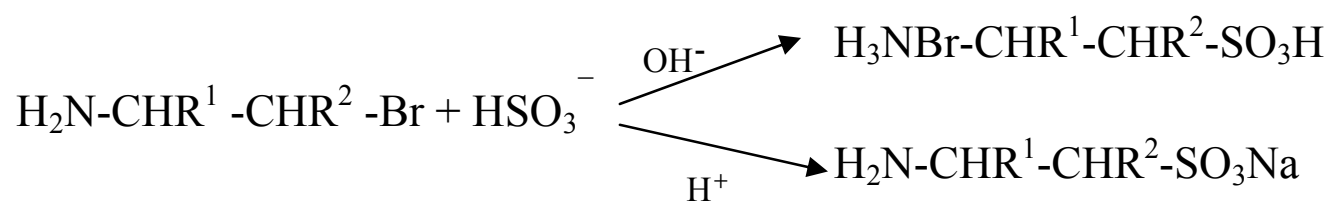

Whence

$\begin{array}{lllll}\mathrm{A} & 1 & 2 & 3 & 4 \\ \mathrm{R}^{1} & \mathrm{CH}_{3} & \mathrm{CH}_{3} & \mathrm{C}_{2} \mathrm{H}_{5} & \mathrm{C}_{3} \mathrm{H}_{7} \\ \mathrm{R}^{2} & \mathrm{H} & \mathrm{CH}_{3} & \mathrm{H} & \mathrm{H}\end{array}$

While series B : proceeds according to:

$\mathrm{H}_{2} \mathrm{~N}-\mathrm{CHR}^{3}-\left(\mathrm{CH}_{2}\right)_{\mathrm{n}}-\mathrm{CHR}^{4}-\mathrm{Br}+\mathrm{HSO}_{3} \stackrel{-}{\longrightarrow} \underset{\mathrm{H}^{+}}{\longrightarrow} \mathrm{H}_{2} \mathrm{~N}-\mathrm{CHR}_{3}^{3}-\left(\mathrm{CH}_{2}\right)_{\mathrm{n}}-\mathrm{CHR}^{-}-\mathrm{SO}_{3} \mathrm{Na}$

$\begin{array}{lllll}\mathrm{B} & 5 & 6 & 7 & 8 \\ \mathrm{n} & 0 & 0 & 1 & 2 \\ \mathrm{R}^{3} & \mathrm{H} & \mathrm{H} & \mathrm{H} & \mathrm{H} \\ \mathrm{R}^{4} & \mathrm{H} & \mathrm{CH}_{3} & \mathrm{H} & \mathrm{H}\end{array}$

It is revealed that our results are best fit to the mechanistic route that was previously suggested, (Dabbagh, 1996) and (Ahmad, 1986). 
The fate of amino alkyl bromide, considered during the course of the present investigation, is predominantly due to its reaction with hydrosulfite ion. Two dominant substitution pathways are considered via reactions 1 (acidic medium) and 2 (basic and neutral medium) which involve transition states TS1 and TS2, respectively. Optimized geometries of reactant, products and transition states are shown in Fig. 1.

Reactant

TS1

TS2
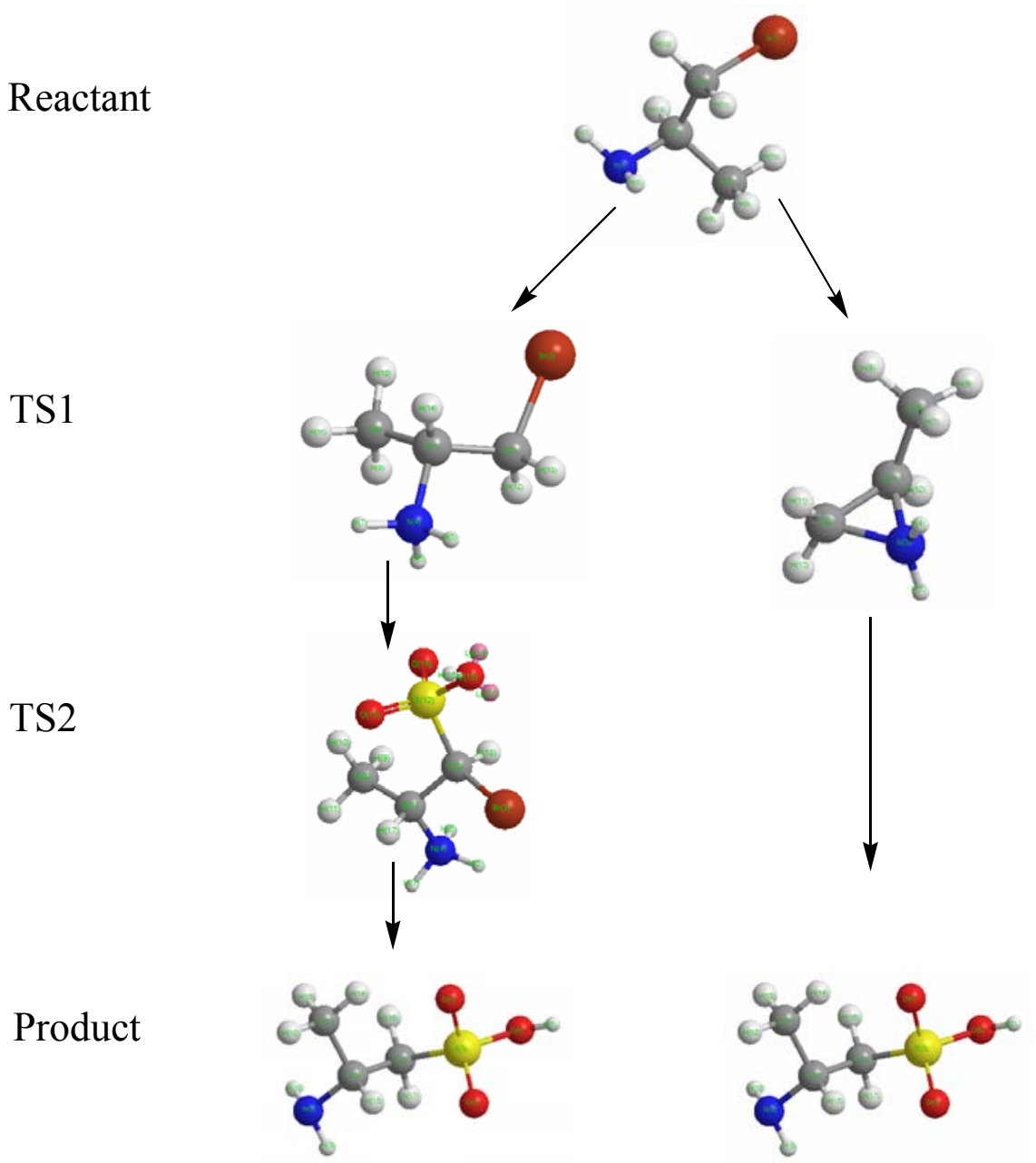

Fig. 1: Optimized geometries of reactant, transition states, and products involved in the reaction of amino alkyl bromide; left: reaction in acidic medium, right: in basic and neutral medium.

\section{Heat of Formation and Steric Energy}

The present study provides a first complete computational energy and entropy profiles for the two series of this type of reaction. The difference in the ground state energies, $\left(\mathrm{H}_{\mathrm{f}}\right)$, of both series as well as transition states and products are attributable to the bulk of the substituent groups, as shown in Table (1). It can also be noticed from Table (1), that the heat of formation of all reactions, $\Delta \mathrm{H}^{\circ}$, for both series are almost constant which indicate that all the products, relatively to their analogue reactants, in all media are almost with same stability. 
The increase of substituent's size also caused in an increase in the steric energies of the compounds. The heats of formation and steric energies of reactants, transition states, and products are calculated by AM1 method and tabulated in Tables $1 \& 2$ respectively.

An equation for evaluation of the ground state energy (heat of formation, $\Delta \mathrm{H}_{\mathrm{f}}^{\neq}$) of the intermediate has been derived using the SPSS statistics programme version 17.0. as below:

$\Delta \mathrm{H}_{\mathrm{f} \text { (intermediate) }}^{\neq}=33.603+0.183 \mathrm{H}_{\mathrm{f}}(\mathrm{R})-0.186 \mathrm{H}_{\mathrm{f}}(\mathrm{P})$

Calculations were only carried out in acidic medium at $\mathrm{pH}=5$. The results are tabulated in Table 1. In fact, and according to the transition state theory, $\Delta \mathrm{H}_{\mathrm{f} \text { (intermediate) }}^{\neq}$ is equivalent to activation energy of the reaction and accordingly it is comparable with those obtained in previous work (Dabbagh,1996). The difference between calculated and experimental values for all reactions are generally small and vary within $20 \mathrm{~kJ} \mathrm{~mol}^{-1}$.

Table 1: Heat of formation $\left(\mathrm{H}_{\mathrm{f}}\right)$ of reactants, transition states, and products calculated by AM1 method.

\begin{tabular}{|c|c|c|c|c|c|c|c|}
\hline & compound & $\begin{array}{c}\mathrm{H}_{\mathrm{f}}(\mathrm{R}) \\
\mathrm{kJ} \mathrm{mol}^{-1}\end{array}$ & $\begin{array}{l}\mathrm{H}_{\mathrm{f}} \text { (TS1) } \\
\mathrm{kJ} \mathrm{mol}^{-1}\end{array}$ & $\begin{array}{l}\mathrm{H}_{\mathrm{f}}(\mathrm{TS} 2) \\
\mathrm{kJ} \mathrm{mol}^{-1}\end{array}$ & $\begin{array}{c}\mathrm{H}_{\mathrm{f}}(\mathbf{P}) \\
\mathrm{kJ} \mathrm{mol}^{-1}\end{array}$ & $\begin{array}{c}\Delta \mathbf{H}_{\mathbf{f}}^{\circ}(\text { reaction }) \\
\mathbf{k J ~ m o l}^{-1}\end{array}$ & $\begin{array}{c}\Delta \mathbf{H}_{\mathrm{f}}^{\ddagger} \\
\text { (intermediate) } \\
\mathrm{kJ} \mathrm{mol}^{-1}\end{array}$ \\
\hline \multirow{8}{*}{$\begin{array}{c}\text { Acidic } \\
\text { medium }\end{array}$} & A1 & -57.10 & 595.43 & 139.95 & -557.04 & -499.94 & 126.76 \\
\hline & $\mathrm{A} 2$ & -73.68 & 573.37 & 127.04 & -575.67 & -501.99 & 127.19 \\
\hline & A3 & -81.10 & 562.37 & 103.50 & -584.27 & -503.17 & 127.44 \\
\hline & A4 & -108.28 & 533.96 & 76.83 & -608.95 & -500.67 & 127.05 \\
\hline & B5 & -35.73 & 625.37 & 156.30 & -537.93 & -502.20 & 127.12 \\
\hline & B6 & -67.25 & 591.65 & 171.77 & -566.70 & -499.45 & 126.70 \\
\hline & B7 & -73.35 & 586.98 & 102.52 & -572.95 & -499.6 & 126.75 \\
\hline & B8 & -102.13 & 551.95 & 48.63 & -602.68 & -500.55 & 127.01 \\
\hline \multirow{8}{*}{$\begin{array}{c}\text { Basic } \\
\text { medium }\end{array}$} & A1 & -57.10 & 740.51 & $\longrightarrow$ & -557.04 & -499.94 & $\longrightarrow$ \\
\hline & $\mathrm{A} 2$ & -73.68 & 694.35 & $\longrightarrow$ & -575.67 & -501.99 & 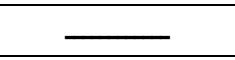 \\
\hline & A3 & -81.10 & 711.20 & 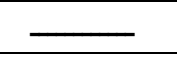 & -584.27 & -503.17 & 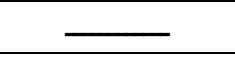 \\
\hline & A4 & -108.28 & 681.25 & & -608.95 & -500.67 & \\
\hline & B5 & -35.73 & 787.94 & - & -537.93 & -502.20 & - \\
\hline & B6 & -67.25 & 740.51 & $\longrightarrow$ & -566.70 & -499.45 & \\
\hline & B7 & -73.35 & 709.77 & $\longrightarrow$ & -572.95 & -499.60 & 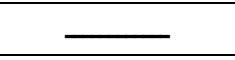 \\
\hline & B8 & -102.13 & 585.09 & - & -602.68 & -500.55 & $\bar{L}$ \\
\hline
\end{tabular}

To ascertain the existence of transition state on the corresponding potential energy surface, intrinsic reaction path calculations (IRC) are also performed for each transition state. The IRC plots shown in Figures 2 and 3 reveal the transition state structure moving energetically downhill until the reactant and products are reached as complementary end point of the reaction path (Singh et al., 2010). 


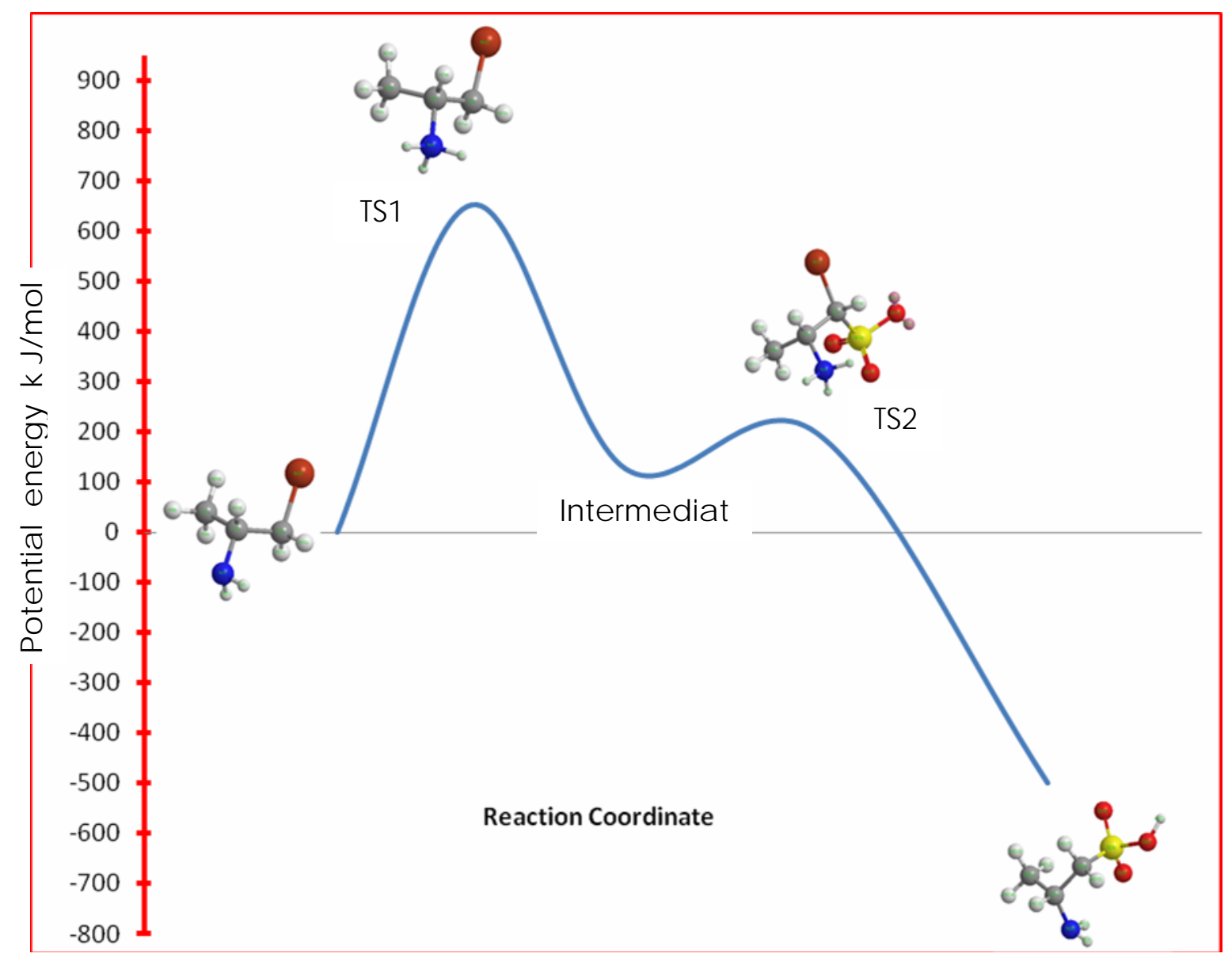

Fig. 2: IRC plot showing the transition states TS1 and TS2 for acidic pathway.

The reactant, transition state and product are also shown along the reaction path. 


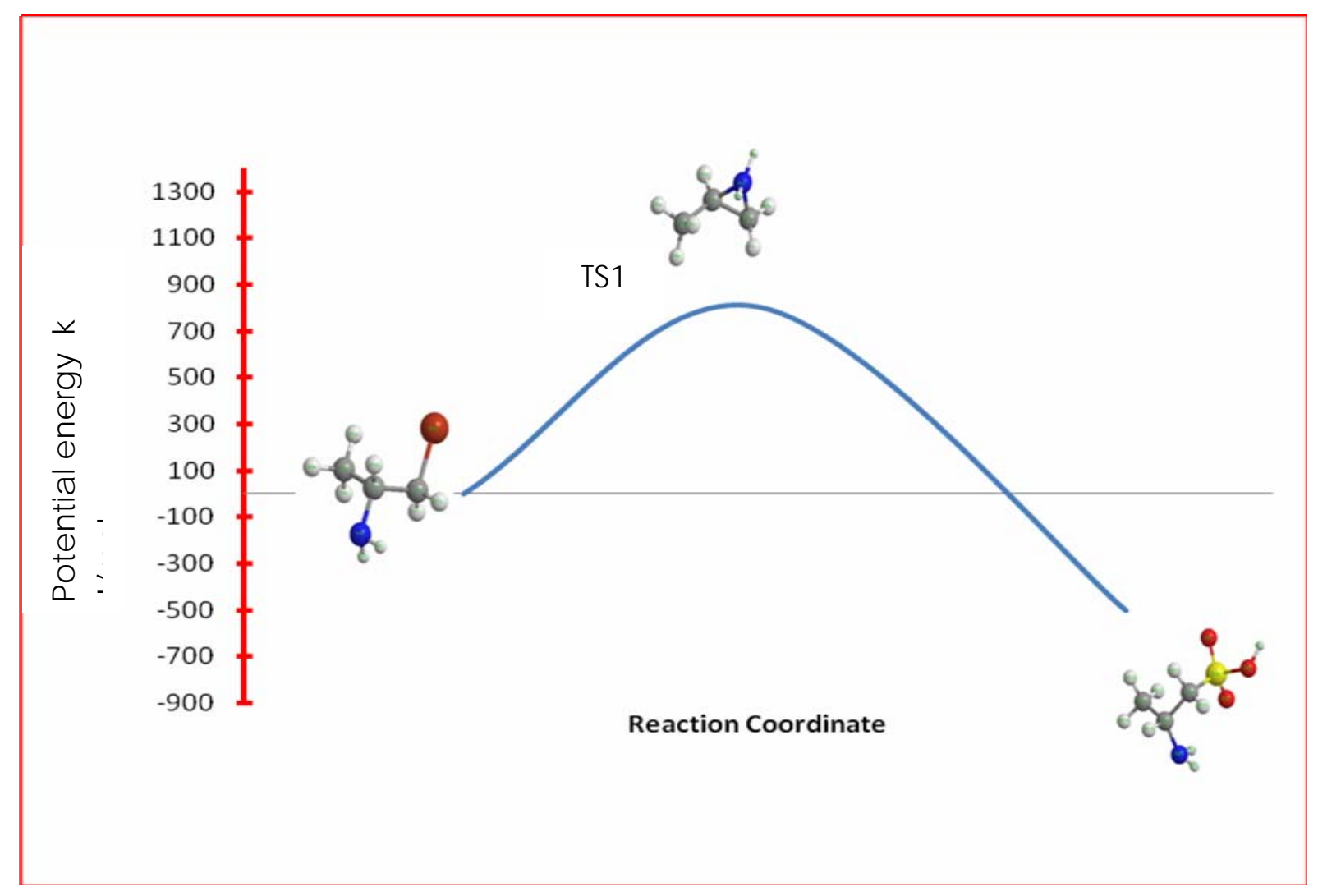

Fig.3: IRC plot showing the transition state TS1 for basic pathway.

The reactant, transition state and products are also shown along the reaction path.

Single point energy calculations of the reactants, transition states, and products are performed using AM1 method. In this method, the optimized geometry was taken into account. The calculated total energies are corrected for zero-point energy. Energy barriers for the substitution reactions via TS1 and TS2, respectively are evaluated from the corrected total energies, as shown Fig. 4 and 5 (Singh et al., 2010). The energy diagram, constructed with the zero-point corrected energies data relative to the ground state energy of AAB arbitrarily taken as zero, is plotted in Fig. 4. The barrier height of about $150.0 \mathrm{~kJ} \mathrm{~mol}^{-1}$ for acidic medium substitution is lower than that of basic or neutral medium substitution. This makes the acidic substitution pathway to be the dominant process for the substitution of these amino alkyl bromide. 


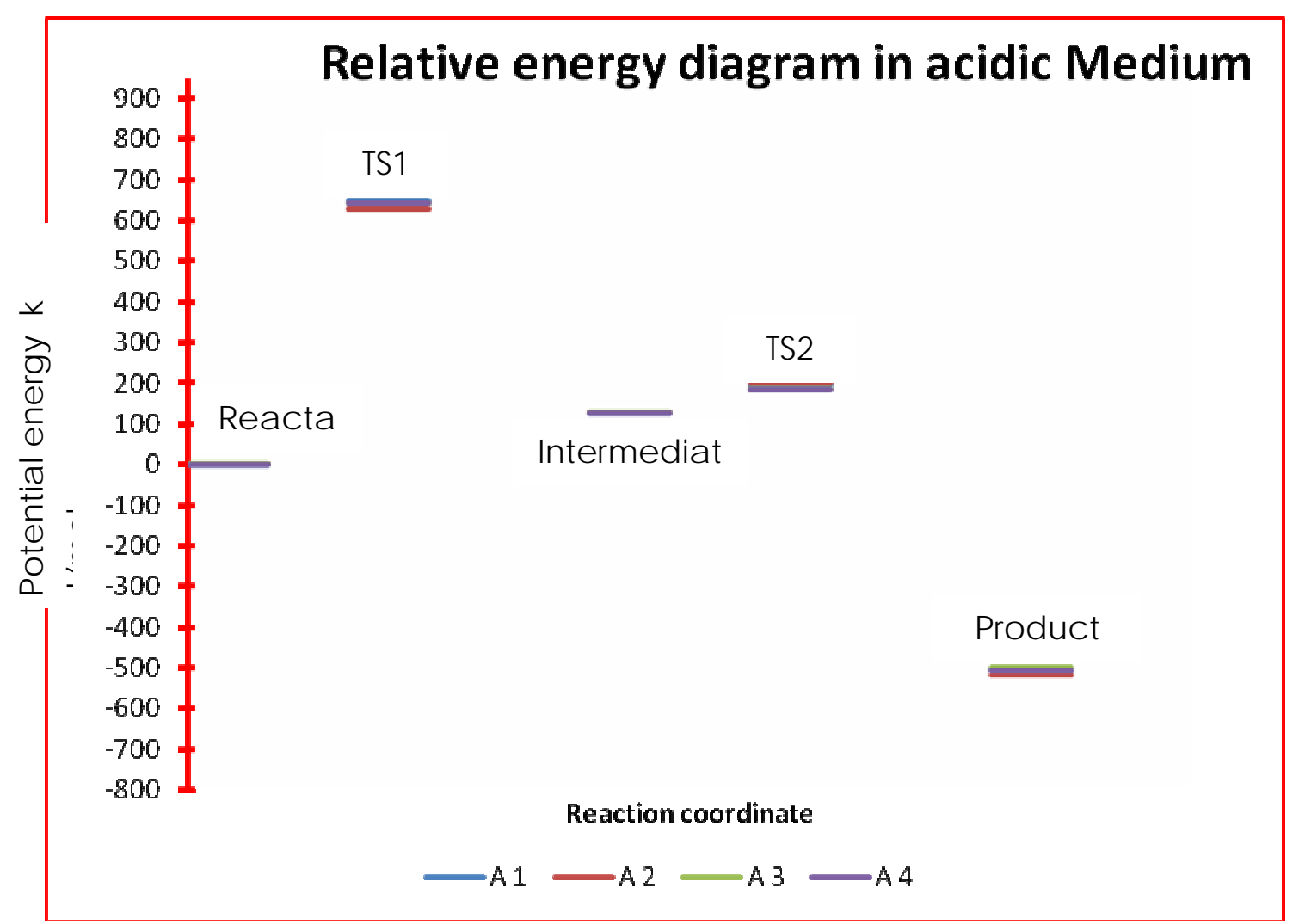

Fig. 4: Relative energy diagram for reactions of $A A B$ in acidic medium.

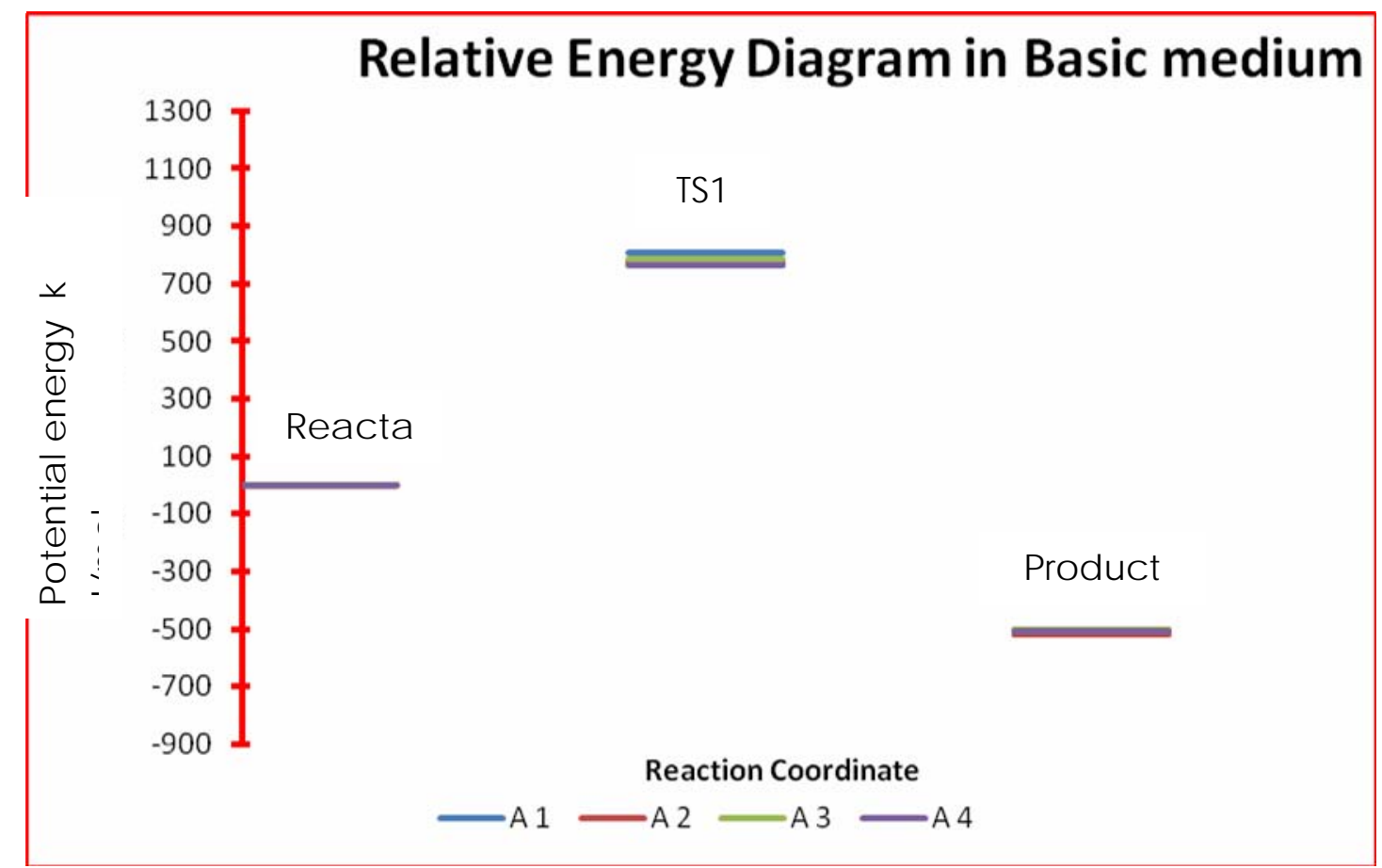

Fig. 5: Relative energy diagram for reactions of $\mathrm{AAB}$ in basic and neutral media 


\section{Mechanism of the Reaction}

The amino group can be considered as excellent nucleophile in basic medium (Elvidge, 1981, Hansen, 1965 and Cohen, 1952, Dabbagh 1996). Therefore, the reaction may proceed through the neighboring-group participation mechanism. In fact steric crowding also plays an important role in facilitating the reaction process, as shown in Table 2 .

Table 2: Steric energy (SE) of reactants, transition states, and products calculated by AM1 method.

\begin{tabular}{|c|c|c|c|c|c|}
\hline & compound & $\begin{array}{c}\text { SER } \\
\text { kJ } \\
\mathrm{mol}^{-1}\end{array}$ & $\begin{array}{c}\text { SETS1 } \\
\text { kJ } \\
\text { mol }^{-1}\end{array}$ & $\begin{array}{c}\text { SETS2 } \\
\text { kJ mol }^{-1}\end{array}$ & $\begin{array}{c}\text { SEP } \\
\text { kJ } \\
\text { mol }^{-1}\end{array}$ \\
\hline \multirow{8}{*}{$\begin{array}{c}\text { Acidic } \\
\text { medium }\end{array}$} & A1 & 18.77 & 21.16 & 155.65 & 109.18 \\
\hline & A2 & 30.76 & 32.97 & 180.27 & 112.79 \\
\hline & A3 & 32.96 & 30.41 & 178.74 & 117.44 \\
\hline & A4 & 37.52 & 38.58 & 193.19 & 131.41 \\
\hline & B5 & 9.075 & 11.93 & 156.30 & 101.73 \\
\hline & B6 & 20.046 & 20.74 & 171.77 & 103.32 \\
\hline & B7 & 16.82 & 30.13 & 102.52 & 104.13 \\
\hline & B8 & 22.05 & 30.53 & 48.63 & 107.43 \\
\hline \multirow{8}{*}{$\begin{array}{c}\text { Basic } \\
\text { medium }\end{array}$} & A1 & 18.77 & 520.94 & ---------- & 109.18 \\
\hline & A2 & 30.77 & 525.32 & 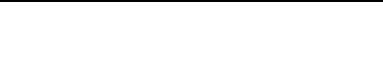 & 112.79 \\
\hline & A3 & 32.96 & 531.92 & --------- & 117.44 \\
\hline & A4 & 37.52 & 533.06 & - - - - - - - - - & 131.41 \\
\hline & B5 & 9.08 & 516.28 & --------- & 101.73 \\
\hline & B6 & 20.05 & 520.90 & - - - - - - - - - & 103.32 \\
\hline & B7 & 16.82 & 146.07 & - - - - - - - - - & 104.13 \\
\hline & B8 & 22.05 & 68.83 & - - - - - - - - - & 107.43 \\
\hline
\end{tabular}


For series A compounds, a three member ring intermediate, aziridine $\mathrm{X}^{*}$, is formed, in a fast step, by the action of neighboring amino group, which acts as nucleophile, pushing out the leaving group, (bromide). The increase in size of the substituents, in this case, increases the steric crowding of the intermediate, while electronic effects increase its stability leading to an increase in steric energy, as shown in (Table 2.)

For series B compounds, a cyclic intermediate is formed in a fast step for the same mentioned reason. The increase in the size of the intermediate cycle increases its stability leading to a vast decrease in steric energy. This mechanism may occur in neutral medium too, due to the same reason.

The nature of the cyclic intermediate was also previously studied in some details and confirmed using salt effect (Dabbagh, 1996). For both series, the second step is expected to involve the external nucleophile, $\left(\mathrm{SO}_{3} \mathrm{H}^{-}\right)$, to push out the amino group in a slow step as shown below:

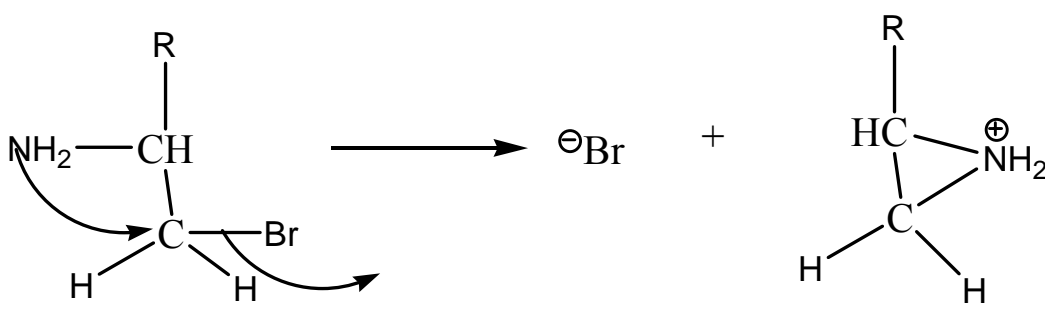<smiles>[R]C1[NH2+]C1[Hg]</smiles><smiles>[R]C(N)CS(=O)(=O)O</smiles>

The $\left(\mathrm{SO}_{3} \mathrm{H}^{-}\right)$group, of course, increases the steric crowding of the TS2 leading to a higher steric energy than TS1.The values are also comparable among each other due to the size effect as discussed before. 
The acidic medium, on the other hand, results in the formation of quaternary ammonium bromide $\left(\mathrm{AH}^{+}\right)$, and sulfonic acid, $\mathrm{H}_{2} \mathrm{SO}_{3}(\mathrm{SH})$, (Elvidge, 1981, Dabbagh, 1996). For this process the steric crowding causes little effect on the reactant molecule leading to least differences in TS1. Thus the reaction may proceed through a completely different mechanism by which a pre-equilibrium involving the attack of the $\mathrm{AH}^{+}$by $\mathrm{SH}$ followed by leaving the substrate $\mathrm{Br}^{-}$in a slow step, (Dabbagh, 1996).<smiles>[R]C(N)C([2H])Br</smiles><smiles>[R]C([NH3+])C([2H])Br</smiles>

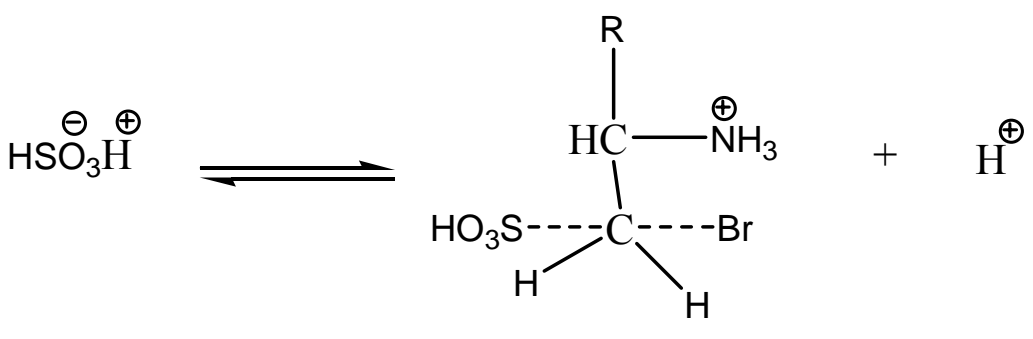<smiles>[R]C([NH3+])[C@@H]([R])Br</smiles><smiles>C[AsH2]O[SiH3]</smiles><smiles>[R]C(N)C([1H])([2H])O</smiles>

Such mechanism in both media are best supported by the kinetic results, (Dabbagh, 1996). The driving force for the stability of the intermediate can be related to the degree of electron efficiency caused by inductive force of substituent, $\mathrm{R}$, groups. The more powerful the electron donating group, the less facile is the attack of the $\mathrm{SO}_{3} \mathrm{H}^{-}$ion on the intermediate. It is not surprising, therefore, to notice that the large differences in steric energies between TS2 and products are related to the degree of electron donating ability of the substituent groups.

It is worth noting that steric energy of compound A2 is attributed to the steric hindrance caused by the methyl group at the alpha position of the alkyl bromide which prevent $\mathrm{SO}_{3} \mathrm{H}^{-}$ion attack. 


\section{REFERENCES}

Ahmed, K. M., (1986). Kinetic studies of reactions of bromo aliphatic amines with sulfite ion. M.Sc. Thesis, Dept. of Chem., College of Science., University of Mosul, Mosul, Iraq.

Cohen, B.; Van Artsdalen, E. R. ; Harris, J. (1952). Reaction kinetics of aliphatic tertiary $\beta$-chlororthylamines in dilute aqueous solution. III Reactions of ethylenimonium ion with certain anions. J. Amer. Chem. Soc., 74, 1878.

Dabbagh, A. M. (1996). Kinetic studies of the reaction of some 2-amino alkyl bromides with hydrosulfite ion in solutions of different $\mathrm{pH}$. Mu'tah J. for Research and Studies, 11, 147.

Elvidge, J. A.; Jones, J. R.; Saieed, M. S. ; . Evanes, E. A ; Warrel, D. C. (1981). mechanistic aspects of the tritiation and deuteriation of taurine. J. Chem. Reaserch, 9, 288.

Guidotti, A. ; Badiami, G. (1971). Potentiation by taurine of inotropic effect of strophanthin-k on guinea pig isolated auricles. Pharmacol. Res. Commun. 3 (1), 29-38.

Hansen, B. (1962). Kinetics of formation and reactions of quaternary ethylenimonium compounds. Acta Chem. Scand., 16, 1945.

Najim, Z. A., (2010). Development of a new set of additives parameters affecting the rate of substitution of bromoalkylamine. Tikrit J. Pure Sci., 15 (1), 244-250.

Saieed, M. S. (2005). Additional factor affecting the rate and mechanism of ring opening reaction. J. Edu. and Sci. 17(4), 18.

Sen, N. P. (1962). Synthesis and properties of homotaurine. Can. J. Chem. 40, 2189-91.

Shigeru, T.; Kazuyoshi, H. ; Akiyuki, Y. ; Kikuo, A. ; Osamu, U. (1972). Treating hypertension with 3-aminopropanesulfonic acid compositions. Chem. Abstract, 77, $52331 \mathrm{t}$.

Singh, H. T.; Mishra, B. K.; Gour, N. K., (2010). Theoretical Studies of decomposition kinetics of $\mathrm{CF}_{3} \mathrm{CCl}_{2} \mathrm{O}$ radical. Theor. Chem. Acc. 125, 57-64

Tesuji, K. ; Fumio, K. (1975). Homotaurine derivatives. Chem. Abstract. 82, 170049h. 